\title{
CADERNOS GESTÃo PÚBLICA E CIDADANIA
}

\section{O GOVERNO MUNICIPAL NO BRASIL: CONSTRUINDO UMA NOVA AGENDA POLÍTICA NA DÉCADA DE 90}

José Antonio Gomes de Pinho

Mercejane Wanderley Santana 


\section{Os Autores}

\section{José Antonio Gomes de Pinho}

Doutor pela Universidade de Londres.Professor Adjunto da Escola de Administração/NPG/UFBA.

\section{Mercejane Wanderley Santana}

Mestre em Administração pelo NPGA/UFBA

*Este trabalho é uma versão ampliada e modificada do artigo "0 QUE FAZ 0 GOVERNO MUNICIPAL NO BRASIL? Realizações, tendências e perspectivas", apresentado no ENANPAD 2000. 


\section{ÍNDICE}

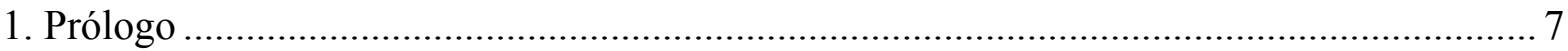

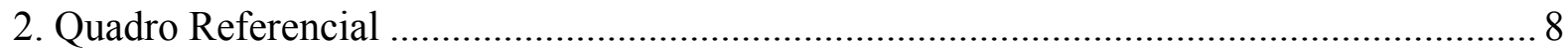

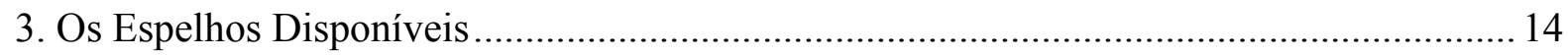

4. O Que Fazem os Governos Municipais...................................................................... 17

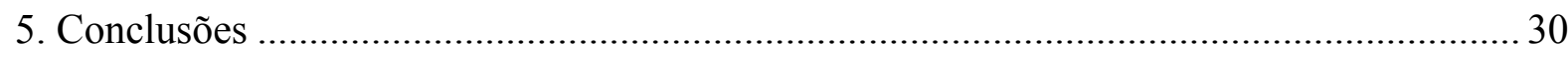

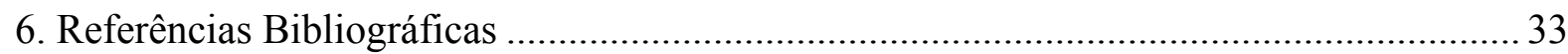




\section{Resumo}

O Estado vem passando por inúmeras transformações no contexto contemporâneo. A esfera municipal, principalmente, tem sido alvo de atenção pela responsabilidade, valorização e expectativas que lhe são atribuídas num forçado redesenho do Estado em resposta a uma situação de crise. A trajetória dos governos municipais revela uma gama de soluções e alternativas inovadoras no desempenho deste novo papel, que passam por políticas de descentralização, participação, saúde, educação, emprego e renda, democratização, desenvolvimento local, entre outras. 0 objetivo deste artigo é contribuir para o entendimento, de uma forma crítica, desse processo pelo qual passa o governo municipal no Brasil nos últimos anos, identificando intervenções, novas configurações e sinalizando tendências que guardadas as devidas especificidades poderão ser reproduzidas em outras realidades. Para tanto são utilizados como material empírico cerca de 400 experiências inscritas em 1996, 1997, 1988 e 1999 no Programa Gestão Pública e Cidadania da EAESP/Fundação Getulio Vargas, Fundação Ford, BNDES, com a participação de outras instituições. 


\section{PRÓlOGO}

É inevitável observar que o mundo contemporâneo vem passando por inúmeras e intensas transformações nos últimos anos resultado de uma série de crises que levam a um reposicionamento de diversos atores sociais. Nesse processo, o Estado e a Sociedade são atores estratégicos e sofrem mudanças radicais em suas estruturas e relações. Dentro do Estado mais especificamente os governos passam a assumir papéis diferenciados dos até então desempenhados. Mudam os governos não só por movimentos endógenos mas mudam também porque muda a sociedade e assim, desestabiliza-se o equilíbrio anterior. Por outro lado, não dá para se pensar em governos de uma maneira homogênea, pois também mudam os governos dentro do sub-sistema governo. A tendência, já concretizada na prática, é de uma valorização dos níveis sub-nacionais de governo em detrimento do governo central. As razões são múltiplas e conhecidas, mas valeria a pena ressaltar o esgotamento da capacidade de lidar com problemas complexos e extensos por parte dos governos centrais o que leva a transferência desses problemas para os níveis sub-nacionais, principalmente o municipal. 0 argumento é procedente: ao se partir um problema ele se divide em partes menores e isso torna mais fácil o seu tratamento. Além disso ao se transferir o problema para o nível municipal, este seria o mais habilitado a enfrentá-lo dado que a sociedade está mais próxima do governo e, assim, a definição das soluções, acompanhamento, interações e controles seriam mais factíveis em menores agregados do que maiores, muitas vezes gigantescos. Este argumento já carrega o pressuposto de que o governo sozinho não apresenta condições de enfrentar diversos problemas, tendo que recorrer à parcerias e interações com a sociedade.

Feitas essas observações preliminares, podemos concluir que o governo municipal no Brasil, para não mencionar outros países, tem assumido importância cada vez mais relevante. Visto de outra forma, espera-se cada vez mais do governo municipal. Isto posto, este artigo visa identificar o que faz, o que tem feito, em que áreas tem atuado o governo municipal no Brasil nos últimos anos. 0 objetivo é detectar configurações que se reproduzem e identificar tendências no sentido de localizar uma possível nova plataforma de atuação dos governos municipais. Isto é, identificar um conjunto de intervenções que possam ser reproduzidas em outros contextos, guardadas, evidentemente, as peculiaridades locais. Para tanto, valemo-nos de um universo constituído pelos projetos do nível sub-nacional inscritos no Programa Gestão Pública e Cidadania, iniciativa da EAESP/ Fundação Getúlio Vargas, Fundação Ford, BNDES com participação de diversas 
instituições nacionais. Este trabalho apropria-se dos projetos inscritos nos anos de 1996 a 1999 debruçando-se sobre os 100 projetos semifinalistas de cada ano. Mesmo deixando de lado as iniciativas do nível estadual e de comunidades indígenas, temos à disposição um universo apreciável de projetos a serem analisados. Pela credibilidade alcançada por este Programa acreditamos que o material empírico investigado reflete de forma fidedigna o que acontece no nível municipal de forma generalizada no País.

\section{QUADRO REFERENCIAL}

De forma explícita assumimos que este trabalho não pretende fazer um esforço de construção teórica do nível local/municipal, mas recolher reflexões feitas por diversos estudiosos sobre a questão ao examinarem todo o processo de valorização do município. Chamamos este conjunto de reflexões de quadro referencial, e será um guia para nossa análise. Em outras palavras, visamos confrontar como as percepções desses analistas batem com uma análise empírico-reflexiva por nós desenvolvida. Podemos iniciar dizendo que do poder local não se espera pouco, ao contrário, já que tem sido visto como "espaço privilegiado para a realização da democracia, da participação cidadã e de iniciativas econômicas e sociais" (Costa: 1996: 113). Por outro lado, "o conceito de descentralização é vago e ambíguo" e assenta-se na expectativa que o conceito traz "de prometer mais do que pode cumprir" (Souza: 1996:104). Assim, o debate público sobre a descentralização vem assumindo "um caráter menos apologético" sendo seus "constrangimentos" e suas "vicissitudes" postos agora em discussão (Melo:1996:11). Se, de um lado, o fortalecimento dos níveis sub-nacionais de governo é visto como positivo para a democracia, de outro, a crítica localiza nesses centros "clientelismo e ineficiência" e "ingovernabilidade" além de uma "irresponsabilidade fiscal" que comprometeria os esforços de estabilização desenvolvidos pelo nível central de governo (Melo:1996:11).

Colocadas essas ressalvas, ou melhor feita esta advertência, o concreto é que a partir da Constituição de 1988, "a União perdeu boa parte de seus recursos financeiros para estados e municípios" e, em conseqüência, "importantes tarefas, antes assumidas pelo poder central, têm de ser incorporadas ao âmbito governamental sub-nacional" (Abrucio \& Couto: 1996: 40). Paralelo a isto, ou melhor intrinsecamente ligado a isto, está a própria crise do Estado central que faz com que se esgote sua capacidade relativa de enfrentamento dos problemas. Porém, o nível sub-nacional, e mais detidamente o nível 
municipal, não é mero reflexo do que acontece no plano nacional, mas também começa a desenvolver uma autonomia própria derivada não só de mudanças constitucionais mas também de um novo posicionamento ideológico. Este fica patente nos governos ligados à partidos de esquerda que brandem não só um discurso ideológico alternativo mas buscam soluções inéditas e inovadoras configurando um quadro de possibilidades mais amplas de sucesso (governabilidade) para o nível municipal de governo. Com isto rompem uma "tradição de os municípios estarem sempre de "chapéu na mão" em relação ao governo do estado ou a Brasília" ( Genro: 1997:28).

Assim, a nível geral, podem ser identificadas as seguintes mudanças no âmbito municipal: presença de "um tipo de política de cunho redistributivo e/ou anticíclico para garantir, minimamente, a renda e o emprego dos habitantes ...". Na área social, os gastos com educação e saúde aumentaram significativamente, "o que demonstra o quanto essas unidades têm cada vez mais assumido o papel de welfare". Para viabilizar estas novas funções, "os municípios precisam modificar sua estrutura administrativa e recapacitar-se financeiramente" (Abrucio \& Couto,p. 41). Para esses autores, talvez "a maior novidade em termos de redesenho do Estado no nível local" seja a função de agente de desenvolvimento econômico especialmente no que toca à geração de emprego e renda (idem, p. 41). Diversas ações podem ser encaixadas nesse rótulo o que faz com que este tipo de atuação seja "uma ruptura com formas tradicionais de ação governamental nos municípios", configurando "uma verdadeira reinvenção do governo" estabelecendo "novos padrões de relacionamento entre o Estado e a sociedade" expressos por mecanismos de democracia direta tais como o Orçamento Participativo (idem, p. 41).

A redefinição do papel do Estado no nível municipal abrange três áreas de mudanças: a "estrutura fiscal federativa", as "diferenças socioeconômicas entre os municípios" e a "dinâmica política típica do âmbito municipal" (idem, p. 42). Quanto ao primeiro componente, esses autores propugnam a necessidade imperiosa dos municípios adotarem uma "política de responsabilidade fiscal, elevando sua arrecadação própria". Tal postura se deve à crise do Estado central tornando inviável aos governos municipais recorrerem ao governo central. Na mesma linha encontram-se os governos estaduais (idem, p. 43). Um segundo desafio colocado aos municípios tem sido o da competição entre eles partindo do princípio que não há incentivos à cooperação e que, ao contrário da corrente internacional, no Brasil observa-se a multiplicação de municípios enquanto nos países desenvolvidos tem-se observado a redução de municipalidades como forma de fortalecer o poder local. 0 
terceiro componente aponta para a necessidade da "institucionalização de formas de negociação que incorporem diretamente à discussão, os setores a serem atingidos pelas políticas municipais..." (idem, p. 45). Entre estas formas podem ser apontadas a experiência do orçamento participativo, os conselhos municipais e outros fóruns de consulta. "Note-se que se trata de implementar no município não apenas formas mais democráticas de gestão, mas também mais eficazes para a tomada e implementação de decisões de governo" (idem, p. 45). De modo a enfrentar suas novas atribuições welfaristas, os municípios devem se voltar também para o "estímulo ao desenvolvimento econômico local" consubstanciado no incremento de parcerias com a iniciativa privada, ou seja, "uma nova relação entre o Estado e o setor privado" (idem, p. 46).

Parece haver convergência nesse diagnóstico tanto que Salgado (1996, p. 49) defende que "desenvolver o município, hoje, é gerenciar os problemas fazendo frente à complexidade e 'a incerteza, é melhorar a qualidade dos serviços aos cidadãos e procurar o desenvolvimento humano ao mesmo tempo em que o econômico". Porém este último é amenizado dado que "o papel do município não pode ser revestido da pretensão de realizar o desenvolvimento. Ele é um articulador que reconhece a existência de uma sociedade interessada na melhoria da qualidade de vida" (idem, p. 49). Em outras palavras, o município tem que assumir que houve "incorporação ativa de um novo ator social regulador nos processos econômicos tanto quanto nos processos políticos: a sociedade civil organizada" (idem, p. 49). Assim, os dirigentes municipais percebem que os instrumentos tradicionais de gestão estão esgotados "em face das demandas da comunidade, que se organiza cada vez mais, e das novas condições de comunicação geradas pelo avanço técnico-científico e tecnológico" (idem, p. 49). A situação atual "passa a exigir novas soluções" e respostas "rápidas para questões complexas". As experiências municipais estão no bojo da "transformação do Estado racionalista tecnocrático-autoritário em Estado democrático". Na substância desse novo arranjo estão práticas gerenciais centradas na qualidade e no exercício da participação (idem, p. 49). No tocante à intervenção municipal em áreas ligadas a variáveis macroeconômicas, áreas "aparentemente fora do alcance dos governos locais", mesmo assim têm ocorrido experiências municipais exitosas (idem, p. 50). Comparando intervenções ocorridas na nada longínqua década de 80 com outras mais recentes é possível perceber que "hoje a instância municipal tem empreendido projetos que representam respostas às exigências contemporâneas de mudanças socioeconômicas" (idem, p. 50). Mais especificamente, 
Salgado aponta que "melhoria da qualidade de vida, democratização do poder e defesa do meio ambiente constituem-se bandeiras que estão sendo assumidas com maior consistência, gerando transformações na ação municipal" (idem, p. 50). Como exemplo da primeira área podem ser apontadas as políticas de saúde, e da segunda a formação de Conselhos Municipais e Consórcios Intermunicipais, além da chamada participação comunitária (idem, p. 50). Nesse sentido, é possível identificar "o fato das atuais experiências de gestão caminharem para o abandono de uma cultura administrativa baseada no poder autoritário e centralizado e na concepção da função pública "desprofissionalizada" (idem, p. 50). É possível identificar ainda o abandono de ações ligadas a "maquiagem" urbana passando os municípios a assumirem "questões de maior complexidade"como intervenções na área de abastecimento envolvendo produção, circulação, comercialização e consumo com reflexos na melhoria da qualidade de vida e na distribuição de renda (idem, p. 51). Ao tempo que o abastecimento, por exemplo, começa a ser visto como componente da política de desenvolvimento municipal, ocorre um "declínio da idéia de que desenvolvimento econômico é a industrialização" (idem, p. 51), emergindo áreas tais como agricultura, comércio ou turismo como potenciais a serem aproveitados na perspectiva de geração de emprego e aumento da renda (idem,p. 51). Algumas intervenções na área ambiental indicam que o município está sendo "pensado"além de seus limites geográficos, como é o caso da intervenção em bacias hidrográficas que abrangem vários municípios (idem, p. 51). Vale dizer que "a característica principal dessas iniciativas" reside no aparecimento de "uma comunidade com papel mais ativo frente à agenda pública" (idem, p. 51).

Salgado finaliza com a observação pertinente de que "seria, no mínimo, ingênuo considerar que os governos municipais estejam produzindo interferências que mudem completamente as condições locais, principalmente no que se refere à economia..." dado que a crise é "profunda" (idem, p. 51).

A identificação do nível municipal como o detentor do "maior papel no combate à pobreza e à exclusão social" tem sido pontuado também por organismos internacionais. Através do fortalecimento da descentralização, a participação da sociedade civil e a disseminação de best practices as administrações municipais deixariam a tradicional visão assistencialista passando a adotarem "programas de geração de emprego e renda, ações de solidariedade no combate à fome, investimentos em infra-estrutura urbana, etc ...." (Bava: 1996: 53). Nesta posição, tirada em uma reunião organizada pela ONU, não há, observa Bava, 
"curiosamente", nenhuma menção "às responsabilidades dos governos nacionais no que diz respeito a políticas tão importantes como a de emprego, previdência, assistência à saúde, educação e relações de trabalho" (idem, p. 54), o que pode estar indicando, em nossa visão, uma super valorização do nível municipal no combate à pobreza e às desigualdades.

Em outra reunião de organismos internacionais, neste caso o Banco Mundial, novamente são reconhecidos os efeitos sociais perversos da globalização, os efeitos da revolução tecnológica que dispensa cada vez mais trabalhadores, assim como a incapacidade dos Estados nacionais de implementarem as necessárias políticas públicas e há até mesmo o reconhecimento de que o pagamento da dívida externa pelos países do sul aos do norte é causa da crise, mas as recomendações têm sido no sentido de destacar as chamadas best practices e a capacidade de inovação dos governos municipais no enfrentamento dessa crise (idem, p. 54). Com isto acentua-se "uma perspectiva de tratamento pontual dos problemas sociais a partir dos municípios, novamente negligenciando que esses problemas são gerados por uma lógica que escapa à governabilidade das prefeituras" (idem, p. 54). Parece consolidar-se, assim, uma reforma dos Estados nacionais onde estes estão eximidos das responsabilidades de atender conquistas sociais vistas como direitos universais (idem, p. 54). Por outro lado, esta auto desresponsabilização dos Estados nacionais não tem sido acompanhada da necessária transferência de recursos dos níveis nacional e estadual para os municípios para que estes possam atender suas novas atribuições, o que só faz aumentar a grandiosidade da tarefa dos municípios.

Resultado do esgotamento progressivo da capacidade governativa do Estado central, os governos municipais passam a ter que "atender urgências sociais que transcendem, por suas características, as intervenções limitadas e pontuais que assumiam anteriormente" (idem, p. 57). Por outro lado, as iniciativas inovadoras para diferenciados problemas por parte de governos municipais comprometidos com os interesses da maioria, mostram que a questão do desenvolvimento não é de "domínio exclusivo do governo central nem está determinada por uma lógica nacional que desconhece as oportunidades locais e neutraliza a ação cidadã" (idem, p. 57). Na situação brasileira, onde há uma opção pela submissão aos ditames da globalização e de um modelo neoliberal, a tarefa de despertar o local torna-se mais ainda não só necessária como imprescindível, além de aumentar este desafio. Assim, é que a busca de "um modelo alternativo de desenvolvimento que possa se contrapor ao atual modelo neoliberal talvez seja um dos maiores desafios de nossa época" 
(idem, p. 56). 0 desenvolvimento local tem sido apontado como "uma possível resposta ao aprofundamento da dualização e da exclusão social no país" (idem, p. 58) entendendo-se por um projeto de desenvolvimento local "a possibilidade, por um lado, de articular, a partir de iniciativas dos governos locais, um conjunto heterogêneo de forças sociais locais em torno de um projeto comum e, por outro, de direcionar essa energia para o aproveitamento das oportunidades locais..., enfim, articulando e estimulando uma série de iniciativas que abram novas oportunidades de trabalho, distribuição de renda, mercado" (idem, p. 58).

Podemos, então, resumir as áreas de intervenção e as novas atribuições do governo municipal, segundo os analistas considerados, da seguinte forma: políticas de responsabilidade fiscal, elevando a capacidade de arrecadação própria; reconhecimento da sociedade civil organizada como novo ator social o que leva a institucionalização de mecanismos de democracia direta, como orçamento participativo, conselhos municipais, fóruns de consulta além de parcerias com o setor privado; práticas gerenciais centradas na qualidade e no exercício da participação; intervenções na área de abastecimento envolvendo produção, circulação, comercialização e consumo; defesa do meio ambiente; políticas de cunho redistributivo ou anticíclico para garantir a renda e o emprego; reconhecimento que a industrialização não é o único caminho para o desenvolvimento mas que também a agricultura, comércio e turismo podem ser considerados como setores potenciais de geração de emprego e renda; abandono da visão tradicional assistencialista substituída por políticas mais consistentes de combate à exclusão social e à pobreza e sobretudo um novo papel de agente de desenvolvimento local, desenvolvimento este que abrange o econômico, o social e o humano, uma espécie de welfare municipal. Emerge ainda uma visão crítica das possibilidades da descentralização além das reais possibilidades do município se constituir em agente do desenvolvimento econômico destacando-se, porém, sua capacidade de funcionar como um articulador, um negociador com instâncias da sociedade. Questionam-se o modelo neoliberal e a globalização e seus efeitos perversos na arena onde atuam os governos municipais. 


\section{OS ESPELHOS DISPONÍVEIS}

Antes de apresentarmos nossa forma de ver as experiências municipais vale a pena determonos nas contribuições de autores - autores-espelhos -, que também têm se debruçado sobre este universo do Programa Gestão Pública e Cidadania no sentido de identificar possíveis convergências ou divergências. Farah (1998), tratando de forma mais geral o governo sub-nacional no Brasil, identifica dois eixos principais de políticas sociais promovidas por este nível de governo: 1) novas políticas sociais; 2) novas formas de gestão, novos processos decisórios e novas formas de provisão de serviços públicos (idem). Dentro do primeiro eixo, Novas Políticas, identifica uma primeira tendência de inovação através de mudanças sobre a natureza dos serviços prestados, com repercussões sobre a própria política. Como exemplo, ela apresenta a inflexão na área de saúde, onde a perspectiva preventiva substitui o padrão curativo prevalecente no setor. As diversas políticas deste setor visam não só garantir uma maior democratização do acesso `a saúde como maior eficiência, eficácia e efetividade destas (idem). Uma segunda tendência de inovação encontra-se na área de educação através de políticas de universalização do ensino ao lado de novas políticas de combate à evasão e à repetência e melhoria da qualidade do ensino (idem). Identifica-se ainda uma série de procedimentos inovativos no tocante à percepção da especificidade da clientela como do alunado de áreas rurais envolvidos na produção. Uma terceira tendência, chamada de ampliação do espaço da cidadania, volta-se à programas direcionados à populações normalmente não atendidas pelo setor público, tais como, mulheres, idosos, deficientes, comunidade negra. Ainda nesta ampliação do espaço da cidadania, Farah insere programas e projetos voltados para crianças e adolescentes em situação de risco pessoal ou social dentro de uma nova perspectiva de respeito à direitos ao invés da visão tradicional de caráter assistencialista-repressivo. Uma outra tendência refere-se a programas de geração de emprego e renda e de desenvolvimento local, o que expressa um deslocamento apreciável do raio de ação dos governos locais de prestadores de serviços urbanos clássicos ou de políticas sociais tradicionais, para formuladores e implementadores de políticas voltadas para geração de emprego e renda. Farah observa que estes programas "por si sós não podem ser considerados inovadores, quando inseridos numa perspectiva de curto prazo, de caráter emergencial, e quando tendem a assumir uma feição paternalista" com poucas condições de auto-sustentabilidade. Ela assinala que, no entanto, são identificadas diversas "iniciativas recentes que procuram funcionar como 
estrutura de apoio inicial a atividades de longo prazo, auto-sustentáveis, no sentido de propiciar a emancipação da clientela atendida" (idem).

O segundo eixo de mudança - novas formas de gestão -, comporta também algumas tendências de inovação, sendo a primeira delas mudanças na relação entre Estado e Sociedade Civil com a inclusão de novos atores na formulação e implementação das políticas públicas representada pela participação de entidades da sociedade civil nas políticas públicas. As novas políticas sociais passaram a contar como "um dos componentes centrais, a questão da participação popular, entendida como condição para o exercício pleno de direitos de cidadania" de modo a romper com o antigo caráter excludente e paternalista das políticas (idem). Esta participação popular está presente nas mais diversas áreas: educação, saúde, habitação e desenvolvimento urbano, gestão e planejamento (como nos casos do orçamento participativo). Ainda nesta tendência, Farah aponta a informação ao cidadão como um outro eixo de alteração na relação Estado e cidadão rompendo com as dificuldades de acesso a iinformações básicas sobre direitos dos cidadãos e os próprios serviços. Uma outra expressão desta tendência reside "na maior adequação dos projetos ao público-alvo, rompendo-se com a padronização de caráter nacional que tendia a prevalecer em boa parte das políticas públicas no país" (idem).

Uma segunda tendência neste campo refere-se à gestão de programas e políticas estatais e da própria máquina pública procurando atingir toda a administração municipal ou estadual. Neste caso inserem-se programas e projetos de modernização da gestão em variadas manifestações.

Um outro autor-espelho, Fernando Tenório, tem se constituído um crítico da participação e suas efetivas possibilidades em experiências governamentais postulando que "nem sempre o ponto de partida das experiências esteve localizado na sociedade, mas sim numa decisão tomada de forma independente pelo poder público". Ele pondera que "fugindo de um maniqueísmo simplificador", os projetos se espalham ao longo de um continuam que é limitado de um lado por projetos do tipo "pacotes", entregues de forma pronta e acabada aos beneficiários finais, e de outro, por aqueles voltados para a conquista da autogestão por parte dos beneficiários (Tenório \& Rozenberg:1 997:25). Entre outras observações, ele nota que "para muitas experiências, o simples fato de se procurar parcerias com setores organizados da sociedade civil basta para que reivindiquem o rótulo de gestão participativa, independente do modo como se dá o envolvimento dos sujeitos participantes, ou da forma pela qual foram incluídos no processo decisório" (Tenório \& Cunha: 1998: 
18). Ele identifica que a maioria dos programas e projetos são direcionados para "grupos imersos em situações de exclusão" destacando além de intervenções em áreas de população de baixa renda, iniciativas direcionadas à geração de emprego e renda para pequenos produtores rurais e urbanos, desempregados e subempregados. Ao lado de "questões tradicionais" como saúde, educação, alimentação e habitação emergem intervenções em "áreas cuja consciência de sua importância tem aumentado nos últimos tempos: a preservação do meio ambiente, a democratização da comunicação e a valorização da cultura e do lazer" (Tenório \& Rozenberg, p. 21).

Moura (1998) ao buscar mapear as estratégias e possibilidades de financiamento na gestãodo desenvolvimento local dos 100 projetos selecionados em 1996 e 1997 verifica que as iniciativas "ilustram bem a predominância do enfoque do combate à exclusão social, da geração de emprego e renda e da dinamização da pequena produção" (idem, p.37). Reconhecendo serem incipientes e localizadas as experiências econômicas locais, estas na sua maioria destinam-se a um segmento econômico social à margem do mercado como bóia - frias, pequenos produtores e crianças e adolescentes. Verificou também ações dirigidas para a preservação ambiental, limpeza urbana, denotando a "construção de alternativas de desenvolvimento sustentável" (idem, p. 50). Quanto à questão do financiamento pode registrar a ocorrência de parcerias com universidades, com organizações internacionais, (ONGs), entre esferas de governo e parcerias com o setor privado.

Pinho \& Santana (1998), na tentativa de uma compreensão teórica da inovação na gestão pública, analisam as 100 experiências semifinalistas em 1997 e criam as seguintes categorias de inovação:

a) Gestão democrática que seria "uma gestão participativa, comunitária, sem paternalismo, com combate ao clientelismo" entendendo que "a participação pode se dar em várias esferas: na concepção, no planejamento, nas decisões, na operacionalização";

b) Descentralização e desburocratização dos serviços públicos, considerados como "um movimento no sentido de uma maior democratização" em que a tônica das ações " baseia-se em levar os serviços aos usuários rompendo com as formas centralizadas tradicionais de gestão pública, visando facilitar a vida dos cidadãos";

c) Incorporação dos excluídos (maiorias) e minorias, categoria esta que resulta da "percepção por parte dos governos sub-nacionais da existência de uma situação de exclusão social (...) que precede mesmo a condição de cidadania situando-se no plano humanitário, como por exemplo, a questão da fome e da desnutrição (...)" ; 
d) Valores para trás ou valores tradicionais que se caracterizam pela constatação de que "apesar de todo processo de modernização, com o aniquilamento de valores mais tradicionais, parece haver uma recuperação destes em ações desenvolvidas pelas esferas governamentais", como zelo com o patrimônio público, senso comunitário, calor materno em substituição à incubadora, participação da família no atendimento à saúde,etc;

e) Valores para a frente que seriam aqueles considerados novos "que começam a ser cultivados no presente como resultado de uma nova configuração econômica, social e política", tais como o despertar de uma consciência ecológica, ambiental expressos na preservação de recursos naturais, redução do consumo de água, controle biológico de pragas, recuperação de matas, coleta seletiva, reciclagem de papel, etc. Também são considerados "valores para a frente" atenção à terceira idade, prevenção ao uso de drogas, despertar o hábito da leitura em populações de baixa renda, programas de sáude voltados à saúde e não à doença, conscientização de problemas de trânsito, etc.

Concluem que "a inovação em si já é uma admissão de que determinadas velhas estruturas já não dão mais respostas aos problemas. No caso da gestão pública, ou seja, caso de um sistema social, a inovação torna-se praticamente significado de mudança de postura, de posicionamento ideológico, do que mais precisamente inovação tecnológica" "(...) constitui-se uma série de ações pontuais mas que introduzem posições e valores de ruptura com a situação histórica do Brasil".

\section{O QUE FAZEM OS GOVERNOS MUNICIPAIS}

Nosso objetivo agora é debulhar as experiências semifinalistas participantes do Programa Gestão Pública e Cidadania em quatro anos: 1996, 97, 98 e 99. A partir do material analisado nosso esforço direciona-se no sentido de criar compartimentos onde possam ser encaixados os projetos municipais. Pensamos em dois grandes compartimentos de políticas municipais: políticas horizontais e políticas transversais. No primeiro compartimento inserem-se todas aquelas políticas concretas de setores bem explícitos que possam ser pontuais ou mesmo mais abrangentes. No segundo compartimento incluem-se principalmente aquelas políticas que possuem um caráter mais difuso, abstrato. São transversais essas políticas porque perpassam, atravessam todas ou quase todas as políticas horizontais. Em outras palavras, as políticas transversais só existem concretamente se existem as políticas horizontais, estas tornam-se o veículo daquelas. Se as políticas horizontais não existem as transversais são apenas declarações de intenções, princípios. É o caso, por exemplo, da democratização. Esta não existe em abstrato, precisa de ações específicas para se concretizar. As políticas horizontais podem conter, ter conteúdos 
transversais, mas também podem não tê-lo. Por exemplo, políticas habitacionais podem estar marcadas por procedimentos democráticos ou não.

Comecemos pelas políticas horizontais. Neste conjunto arrolamos os seguintes setores de intervenção que aparecem com recorrência no material analisado: meio ambiente, saúde, educação, alimentação e abastecimento, habitação e urbanização, crianças e adolescentes, emprego e renda, projetos agrícolas. Por políticas transversais entendemos: democratização e cidadania, participação popular, combate à pobreza, incorporação dos excluídos. Criamos ainda o compartimento políticas horizontais emergentes para abrigar políticas que já tem alguma expressividade mas que ainda não aparecem com muita frequência, tais como, reforma financeira, cultura e lazer, e atenção à mulher.

\subsection{Políticas Horizontais}

Debulhando cada uma delas podemos tecer os seguintes comentários esclarecendo antecipadamente que não faremos menção a cada uma das experiências analisadas sendo as ponderações aqui colocadas referidas ao conjunto, ao bloco de programas e projetos analisados buscando identificar comportamentos cristalizados e tendências.

1. Meio Ambiente: esta se constitui uma das áreas mais recorrentes de intervenção do poder público municipal. Pode-se perceber, pela forma como são apresentados os projetos, como em determinados municípios já há uma consciência ecológica formada. Esta constatação é importante quando se percebe que, no contexto geral, a sociedade ainda não está suficientemente desperta para este problema, não havendo uma consciência formada ou razoavelmente disseminada. Por outro lado, um dos obstáculos enfrentados tem sido"a inexistência de massa crítica local" para tratar o assunto. Apesar da degradação ambiental que se verifica no Brasil em geral (queimadas, desmatamentos gigantescos, alterações de micro-climas, etc), parece possível identificar uma preocupação de municipalidades em salvar o "seu" meio ambiente, a "sua" água. Em outras palavras, frente à impossibilidade de administrações municipais ecoconscientes de resolverem os graves problemas ambientais nacionais, pelo menos enfrentam e resolvem os seus problemas dentro dos seus espaços territoriais. Assim, essas iniciativas são altamente meritórias e, muitas, com capacidade de êxito em sua propagação 
Pelo material analisado, classificamos essas ações em meio ambiente em ações pontuais e ações macro. Por ações pontuais entendemos aqueles normalmente empreendidas no meio urbano, tais como, coleta e tratamento ambientalmente correto de resíduos sólidos para evitar contaminação do meio ambiente, coleta seletiva de lixo e reciclagem, coleta e tratamento de esgoto sanitário por processo biológico, qualidade e controle de perdas de água tratada, etc. Ações macro referem-se à observação da vida de uma forma mais abrangente, principalmente da água (questão central no século XXI) localizadas normalmente fora das áreas urbanas. Estão neste elenco ações relativas à ocupação racional de áreas rurais sub-utilizadas ou degradadas, preservação de manguezais, substituição de atividades extrativistas delapidadoras do meio-ambiente por culturas não agressoras do meio-ambiente, garantindo a geração de renda e evitando o desmatamento, recomposição e reflorestamento de matas com introdução de plantações nativas, além do impedimento de desmatamentos adicionais, controle biológico, controle de ocupação de margens de rios, reflorestamento de encostas de risco, combate à degradação e recuperação de bacias hidrográficas normalmente envolvendo diversos municípios, educação ambiental. Projetos deste tipo acabam levando à formação de consórcios intermunicipais, o que revela o despertar de uma consciência de necessidade de agregação de instâncias municipais para resolver problemas comuns.

Pode-se perceber que muitas ações são constituídas de soluções de baixo custo e alta eficiência. Identificam-se políticas que objetivam transformar produtores rurais em agentes ecológicos capazes de atuarem no meio-ambiente de "forma racional e equilibrada" e não destruindo este meio-ambiente, transformando-os em aliados na luta pela preservação da biodiversidade. Embora existam muitos projetos de reciclagem, chama a atenção o fato deste tipo de intervenção ainda não estar disseminado por grande parte dos municípios brasileiros, dados os seus inegáveis efeitos positivos, quer do ponto de vista ecológico, quer econômico. 0 maior impedimento à implantação e disseminação de projetos parece residir na falta de uma cultura preservacionista e de respeito ao meio ambiente. Em alguns casos nota-se consciência de que mudanças simples podem levar a resultados maiores. É o caso de um Programa de Coleta Seletiva em escolas, onde a mudança de hábitos dos alunos com relação ao destino final do lixo, leva-os a transmitirem os conhecimentos a seus familiares, vizinhos, etc., a sociedade civil em geral. 
2. Saúde: os resultados encontrados convergem claramente com o apontado por Farah (1998) e por Pinho \& Santana (1998) que também detectam uma mudança qualitativa no enfoque da questão da saúde nos últimos anos. Farah se refere a uma ênfase na saúde preventiva em substituição ao enfoque tradicional de uma medicina curativa. Pinho \& Santana criam a categoria "valores para trás" para expressar o retorno de práticas e posicionamentos de um passado nem tão distante mas que foi substituído pela fúria tecnológica. Nesses dois casos se encaixam programas como médico de família (muito recorrente), atendimento preventivo, atenção à gestantes, parturientes e recém-nascidos, valorização do aleitamento materno, programas de combate à desnutrição com soluções simples, atendimento domiciliar, humanização do atendimento, cultivo de plantas medicinais para a comunidade, enfim, uma mudança de paradigma que elege o coletivo em vez do indivíduo como foco de atenção, e, a saúde em vez da doença. Esta ênfase na saúde não resulta apenas das mudanças a partir da Constituição de 1988 com a municipalização da saúde, mas expressa-se também pela deflagração de políticas inovadoras, "novas" (antigas) formas de abordagem. Pode-se perceber também um número significativo de intervenções em populações rurais deslocando a área tradicional de intervenção e "privilegiamento" do urbano para o rural. Melhor dizendo, o rural também passa a ser considerado. As políticas de saúde também ousam no tocante à reversão do modelo manicomial tradicional, baseado em internamento, promovendo a reinserção familiar e comunitária do paciente. Chama a atenção nos projetos analisados a quantidade de políticas municipais voltadas para a saúde mental, o que poderia estar indicando que a sociedade contemporânea ou estaria mais doente, ou mais aberta e disposta a enfrentar esta realidade. Frente a essa situação, nota-se a busca de soluções alternativas que, além das mencionadas, mobilizam também agentes comunitários, além de práticas terapêuticas alternativas que estimulam as potencialidades dos envolvidos. Passam também a se voltar para o atendimento de minorias anteriormente marginalizadas (caso de surdos e cegos). Emergem também iniciativas de atenção à drogas, problema contemporâneo que anteriormente não constava dos projetos de saúde.

Pôde-se observar também que o nível municipal em muitos casos não fica esperando as soluções/saídas virem dos governos federal e estadual, notando-se uma atitude pró-ativa neste setor acompanhado de medidas de baixo custo, no sentido de reduzir despesas, rompendo com a posição do Estado perdulário. Nota-se em algumas 
administrações uma postura não conformista com a aceitação da pobreza e mesmo, com recursos escassos e limitados, buscam alternativas para enfrentar a pobreza e os problemas de saúde, não aguardando surgirem as condições ideais, adequadas, mas adequando as soluções aos recursos disponíveis. Identificam-se ainda políticas que envolvem crianças e adolescentes no combate a epidemias (Equipe Caça-Dengue) mobilizando a juventude que, assim adquire consciência social. Observa-se que existe uma postura de mobilizar atores da sociedade civil (Ongs, associações, crianças, adolescentes), constituindo parceiros, para enfrentamento da questão mais ampla da saúde, demonstrando que o governo por si só é incapaz de prover as soluções necessárias, necessitando de uma articulação e do apoio da sociedade civil.

3. Educação: aqui também os resultados encontrados convergem com aqueles de Farah, notando-se uma busca da universalização do ensino acompanhado de uma melhoria incessante deste, com combate específico ao analfabetismo. Nota-se uma disseminação da idéia básica da Bolsa Escola, onde a família recebe recursos financeiros para colocar seus filhos na escola. Em alguns casos essa ação é bem incisiva, mostrando uma preocupação orgânica do governo em atacar o problema como o envolvimento das famílias e a criação das condições necessárias de apoio (transporte, orientação, convites domiciliares, documentação). Esta política ganha maior relevância ainda quando ativada em áreas do interior do Nordeste, indicando como a questão educacional é mobilizadora e está presente nas mentes de muitos dirigentes. Destaque também deve ser dado ao envolvimento das famílias no sentido de combater o problema educacional, mais especificamente à evasão escolar. Percebe-se também uma interface de programas de educação com outras áreas como emprego e renda. Também são identificados projetos que se vinculam à idéia de valores para trás como a disseminação do hábito da leitura e freqüência à bibliotecas, o que também se lastreia na mobilização da sociedade civil. Esses projetos, entre os quais se destaca o Mala do Livro/Bibliotecas Domiciliares, possuem a virtude de atingir populações carentes, expressando a viabilidade de implantar programas de baixo custo, alta qualidade e alta responsabilidade social, atendendo populações extremamente carentes que normalmente são deixadas à margem de projetos por conta exatamente de sua carência, reforçando um círculo vicioso e perverso. As questões da droga e da violência também emergem em iniciativas que vinculam o enfrentamento desses problemas à programas de articulação entre escola e comunidade. Atendimento 
à populações das áreas rurais também são registrados, mostrando uma tendência de reverter o modelo de atendimento prioritário à áreas urbanas bem como conciliar as especificidades da população rural com a educação ao implantar um programa de estudos concentrado em certos dias da semana. A política educacional é também atrelada `a questão ecológica, assim como volta-se também para populações carcerárias indicando um objetivo de recuperação dos detentos e mostrando uma cidadania pensada de uma forma mais abrangente. Enfim, nota-se uma mobilização em um número significativo de municípios em relação à superação dos problemas educacionais.

4. Alimentação e Abastecimento: neste setor a inovação e a criatividade expressam-se de várias formas mas, fundamentalmente, refletindo posicionamentos políticos de enfrentamento da questão da pobreza, da desnutrição. Aqui estão arrolados tanto programas de abastecimento abrangentes e centralizados como projetos pontuais tais como hortas comunitárias, produção de farinhas e pães enriquecidos com vitaminas, programas específicos de barateamento dos alimentos, despertar de novos hábitos alimentares em populações carentes visando reduzir a desnutrição e doenças. Os arranjos políticos mencionados passam pela disponibilização por parte do setor público de terras ociosas através de arrendamento a agricultores assim como de assistência técnica. Envolvem ainda trocas de cestas básicas por trabalho nas hortas, rompendo com práticas paternalistas, da simples doação de alimentos normalmente com fins eleitoreiros. A iniciativa do governo municipal de atuar no apoio à produção de alimentos, indica que o Estado tem um papel estratégico, que as forças do mercado deixadas por si sós, não só não resolveriam estes problemas como não teriam iniciativa de enfrentá-los. A iniciativa privada só tem iniciativa nas áreas que entende que tem retorno. Dentro do ideário neoliberal, o mercado resolveria isto, mas a realidade mostra que para populações de baixo nível (ou nenhum) de renda isto não acontece. Assim, o governo municipal, tem que intervir mesmo que seja em uma área aparentemente simplória, mas que para esta população e realidade pode representar a vida. Como já apontado anteriormente, muitas vezes, ações simples e de baixo custo podem ter um efeito de grande impacto da redução da pobreza e das condições de vida degradadas. Vale lembrar a estreita associação entre condições de alimentação e capacidade de aprendizagem. Um exemplo dessas ações do governo pode ser visualizado em um programa de comercialização de produtos agrícolas em bairros 
com menor poder aquisitivo a preço acessível, beneficiando dois públicos alvo: o produtor, que se encontra desestruturado e descapitalizado e o consumidor de baixa renda sem capacidade de consumo, ou seja, os dois extremos da pobreza, pequenos produtores e consumidores de baixíssima renda. A intervenção nesta área parece indicar que as condições de pobreza e degradação da vida aumentaram tanto nos últimos anos que muitos governos tomaram consciência dessa situação e resolveram agir, atuando numa área que normalmente não era competência municipal. Mesmo assim, apesar de tantos projetos na área ainda parece faltar a maioria das administrações uma opção preferencial pelos pobres. pequenas oportunidades, mas que representam o preenchimento de um nicho de mercado e oportunidades para os que se engajam nele. Essas realizações contrapõem-se ao modelo econômico central, dado que privilegia a economia de pequenos e micro empresários. Esses governos mostram que não há imobilismo mas também deve haver consciência de que só é possível atuar nas franjas do sistema econômico. Em outras palavras, nenhum governo municipal poderá reverter substancialmente as condições de pobreza locais, nem "salvar" a economia, mas apenas implementar políticas que não estão no horizonte do nível nacional e onde existem esses nichos. Determinados projetos mostram total consciência do problema da empregabilidade no mundo contemporâneo e que a geração de oportunidades de trabalho é necessária e imprescindível e este deve ser um papel do governo. Em um projeto específico existe a afirmação de que "a melhor forma de combatermos a pobreza e seus males é através do trabalho, única forma de dar dignidade ao homem. Queremos criar postos de trabalho remunerados". Esta afirmação questiona o assistencialismo mas ao mesmo tempo o projeto em questão aponta dificuldades de criar uma cultura de empreendedorismo em pequenos municípios.

5. Habitação e Urbanização: ao contrário da política educacional anterior, esta tem sido uma área de tradicional competência do nível municipal e detecta-se uma presença significativa de intervenções nesta área, tendo esta um caráter mais tradicional expressas por mutirões, autoconstrução assistida, envolvimento da comunidade, residindo o elemento inovador na busca de tecnologias alternativas, principalmente com a utilização de materiais não convencionais. Verificouse programa de manutenção da população em áreas de assentamento "subnormais" através de programas de regularização fundiária e melhorias das condições 
infraestruturais e das habitações existentes. Pode-se perceber também políticas de valorização de equipamentos urbanos, tais como praças, associadas à mobilização da população. Projetos nesta área, também rompem com uma visão estanque, promovendo a integração de vários setores como saúde, educação, agricultura, assistência social, emprego.

6. Crianças e Adolescentes: a ação dos governos municipais neste setor reflete novamente a existência de uma situação de degradação, marginalização e pobreza crescentes, resultado de acúmulos de modelos de desenvolvimento perversos agravados nos últimos anos pelo padrão neoliberal. Nesta situação, determinados governos chamam para si a responsabilidade de enfrentar este problema, mostrando que este entrou definitivamente na agenda política. As ações mais recorrentes referem-se à implantação de creches comunitárias, assim como das mais diversas estruturas de acolhimento de crianças e adolescentes em situação de risco e de rua, (através de atividades esportivas e culturais, ambientais, educacionais, de atendimento médico), que por si sós não indicam nenhum posicionamento inovador. Este encontra-se, porém, e fortemente instalado, na conjugação com atividades de caráter profissionalizante e ainda, e principalmente, atividades de formação de consciência da situação de marginalização visando desenvolver a idéia de cidadania. Nesse sentido são discutidas e enfrentadas questões pertinentes à esta população tais como violência, em particular a violência sexual e a violência doméstica, drogas, sexualidade, primeiro emprego, etc., com a participação ativa dos interessados. Registra-se também programa de atendimento a crianças com distúrbios psicossociais, escolares e ou de comportamento. Programas também apontam para a geração de renda dos participantes como uma forma de inserção profissional e de gerar auto-estima assim como o envolvimento das famílias no sentido de sua recuperação. Programas outros combatem o trabalho infantil redirecionando as crianças e adolescentes para a base econômica (e populacional) forte no meio rural, a intervenção em aspectos do rural torna-se questão de sobrevivência do próprio município. Nesse contexto, ganha destaque programas que fazem análises das potencialidades agrícolas e incentivam a agregação de pequenos produtores, percebendo que se esses ficarem desagregados perdem a capacidade de sobrevivência. Do material analisado, pode-se perceber que os projetos agrícolas têm, em boa parte, uma identificação forte com geração de emprego e renda não se esgotando, contudo, neste objetivo. 


\subsection{Políticas Transversais}

A partir da observação do material analisado entendemos como políticas transversais as seguintes: democratização e cidadania, participação popular, combate à pobreza, incorporação dos excluídos. Ao classificar essas categorias como políticas transversais estamos atribuindo à estas a qualidade de atravessarem todas, ou quase todas, as políticas horizontais. Isto quer dizer que várias das políticas horizontais carregam em seu bojo políticas transversais. Mais especificamente, na argumentação das políticas horizontais existem referências explícitas à todas ou algumas políticas transversais, como por exemplo, aos propósitos de democratização, elevação ou introdução da cidadania, redução da pobreza, etc. $\mathrm{Na}$ verdade, ainda existe uma hierarquia dentro dessas políticas transversais e a categoria democratização sendo a mais abrangente, estando nela contida a participação popular. Porém, como a participação popular tem se tornado, e esses projetos expressam isto, uma palavra mágica, carregada de simbolismo, resolvemos deixá-la isolada, com destaque. Esta categorização aproxima-se daquela desenvolvida por Pinho \& Santana (1998) ao criar como categorias de inovação no governo municipal, entre outras, as de Gestão Democrática e Incorporação dos Excluídos e Minorias, colocando dentro da Gestão Democrática o instrumento da participação popular.Tomando cada uma dessas políticas em específico cabem os seguintes comentários:

1. Democratização e Cidadania: embora essas duas categorias sejam as mais difíceis de capturar ao longo dos textos dos projetos analisados, elas aparecem recorrentemente. Ainda que possam ser usadas apenas como palavras de ordem, o que se pode observar na análise dos projetos é que essas palavras se desdobram não só em conceitos, mas em conceitos operacionalizáveis. Pode-se perceber que determinados governos têm um ideário explícito de democratização e não ficam apenas a brandi-lo em forma de discurso, mas partem para operacionalizá-lo na prática, através das políticas horizontais. Vale registrar que, uma das formas recorrentes de expressão desta democratização encontra-se no anti-clientelismo. Em diversos projetos existem referências ao rompimento coma estrutura tradicional de funcionamento da sociedade com base no clientelismo e que este passo caminha no sentido da afirmação de ideais democráticos. Pinho \& Santana (1998) na categoria gestão democrática já afirmavam que "ao se contrapor ao paternalismo e autoritarismo tradicionais, a gestão 
democrática se expressa pela construção de uma nova cultura de relacionamento entre Estado e sociedade civil". Por outro lado, Tenório tem uma visão diferente considerando que o envolvimento da cidadania dá-se como "retórica, e não como ação efetiva no processo de tomada de decisão das políticas públicas" (Tenório:1998:237).

Uma outra forma detectada de democratização repousa na montagem de estruturas governamentais

de disseminação das informações. Na sociedade contemporânea o direito à informação parece que vai se afirmando cada vez mais e com os instrumentos de informática devem se propagar aceleradamente no futuro próximo aperfeiçoando a democracia. Pinho \& Santana (1998) na categoria

valores para frente sinalizavam que "a utilização da informatização para prestação de serviços públicos também foi detectada, tendência que também deve se acentuar no presente e no futuro."

2. Participação Popular: se expressa mais abertamente através do orçamento participativo, orçamento popular, assembléias populares, conselhos populares, planejamento socialmente construído, movimentos organizados da sociedade civil, ouvidoria pública, delegação de poderes às associações de moradores para estas fazerem o gerenciamento de obras, parcerias entre governo e associação de moradores. A participação popular, em variadas formas, pode ser encontrada em várias, se não em todas, políticas horizontais tais como: habitação e urbanização, educação, saúde, políticas agrícolas, meio ambiente, etc. Pode-se perceber que o meio ambiente tem sido usado como uma forma privilegiada de mobilizar a população, principalmente a jovem, incentivando a participação, até com geração de recursos financeiros que revertem para a comunidade, principalmente para a área educacional. Identificam-se ações que oferecem um ganho pecuniário para os participantes, principalmente de baixa renda (troca de lixo por ticket para compra de alimentos). Esta política indica que não existe, por um lado, uma consciência ecológica instalada de forma geral na população (e nem seria de esperar que houvesse), e por outro lado, a pobreza ea carência são grandes. Assim, ao juntar as duas pontas pode levar ao monitoramento da segunda e ao despertar da primeira.

Uma visão otimista entende que dificilmente se faz, ou se fará, política, governo sem participação popular. Por outro lado, parece estar havendo também uma super 
valorização da idéia de participação, uma overdose de participação. Não tendo intenção, neste momento, de teorizar a questão, vale apenas mencionar que com a participação rompe-se a idéia da administração tradicional de que "quem governa é só o governo", passando a incluir no ato de governar também a comunidade. No entanto, essa visão de participação popular ainda é muito restrita, pois subentende-se que quem participa majoritariamente são os "pobres". Não só restrita mas carregando todas as suspeitas que pairam quando a participação envolve esses grupos (clientelismo, riscos de cooptação, instrumentalização, etc). Não há, no geral, uma idéia de envolver a comunidade de uma forma mais ampla. Verifica-se em alguns casos que a população de maior poder aquisitivo considera a participação uma iniciativa importante e demonstra alguma mobilização para encontros e reuniões considerando uma iniciativa importante, mas revela uma resistência à prática efetiva, como na coleta seletiva de lixo. Aí fica a desconfiança maior com a possibilidade de participação popular, pois no momento em que estes "pobres" têm sua demanda específica atendida, tornam-se "menos pobres" e a idéia da participação esvanece-se.

Uma visão crítica deste tema, desenvolvida em diversos tempos por Tenório, aponta entre problemas a questão que "cada gestor e/ou técnico na administração pública nos três níveis de governo - federal, estadual e municipal, interpretam, de forma diferente, como deve ser o processo de envolvimento da cidadania na gestão da coisa pública" (Tenório \& Storino:2000:6). Ainda estaríamos distantes dessa realização pois "o conhecimento exercitado pelas propostas de participação da cidadania em programas e/ou projetos sub-nacionais parece estar fundado em uma pedagogia diretiva, tecnoburocrática, em vez de numa pedagogia emancipatória..." (Tenório:1999:p.237). Sem dúvida, qualquer posicionamento mais claro sobre este tema, polêmico e ainda não plenamente estudado, demanda um aprofundamento da pesquisa, ainda não possível neste momento. Cabe no entanto avançar um pouco na avaliação do orçamento participativo, carro chefe desse posicionamento político-administrativo, após alguns anos de existência desse programa e de sua reaplicabilidade em vários contextos. Assim, em uma dessas experiências, em lpatinga (MG), é apontado que esse programa visa "promover a inversão de prioridades, através do atendimento das necessidades sociais básicas dos cidadãos e de procedimentos democráticos.

Propiciar oportunidade aos cidadãos de participarem efetivamente da discussão, elaboração, acompanhamento e execução do orçamento municipal". 0 projeto tem 
como referência "instituir uma nova forma de administração dos recursos públicos, trazendo a população para compreender, participar, criticar e fiscalizar a sua aplicação". O que o projeto parece apontar é que antes de participar, um problema central e primeiro é compreender a lógica da administração municipal. Em parte, um dos problemas, uma das resistências maiores à participação parece residir justamente na dificuldade de compreender a lógica de funcionamento da administração pública por parte do cidadão comum. Este Programa, o Orçamento Participativo de lpatinga, parece perceber isto. Assim como percebe que há uma frustração da população com o não atendimento de algumas de suas demandas. No aprimoramento do projeto é desenvolvido "uma reavaliação das reivindicações levantadas e não atendidas, com o objetivo de diminuir a frustração da população, uma vez que a receita não atende à demanda". 0 projeto identifica que "a visão bairrista de boa parte dos conselheiros foi um obstáculo enfrentado pela administração pública. Como uma das soluções para este problema a administração criou o programa Caravana da Participação Popular. Com a visita In loco", os conselheiros se conscientizaram que há outras regiões mais necessitadas que a sua, e que há até algumas prioridades mais urgentes".

Observa-se emergir uma consciência de que "o processo de construção da cidade é fruto não só da atuação do poder público, como também da população", como no caso do programa Ribeirão mais Bonita (Ribeirão Pires - SP). De modo a enfrentar a questão da urbanização "é importante que a comunidade faça a sua parte, o que implica em sensibilizar os moradores "quanto a questões de interesse público". A participação se dá através de reuniões recorrentes de setores da população com a administração municipal onde "busca-se trabalhar a idéia de que a transformação da cidade num espaço de qualidade de vida implica num esforço conjunto entre governo e sociedade civil". Existe consciência da forte tradição clientelista e do funcionamento da máquina administrativa na base de " favorecimentos pessoais", por exemplo na prestação de serviços de manutenção "historicamente intermediado pelo Legislativo e usado na barganha política de eleições", que a participação popular poderia contrastar. Neste sentido, a participação tem sido vista como "um elemento pedagógico que possibilita as pessoas desenvolverem uma consciência do seu papel protagonista enquanto cidadão ativo, desenvolvendo novos laços de sociabilidade que possam estimular a organização popular em uma cidade sem tradição e cultura participativa". 
3. Combate à Pobreza: também este tipo de política transversal perpassa várias políticas horizontais. São diversas as referências ao combate à pobreza através de projetos de educação, saúde, habitação, etc., e não só em termos de políticas de emprego e renda. As condições de pobreza crescentes, geradas nas últimas décadas no Brasil pelos vários modelos econômicos excludentes, produziram uma massa de pobres e miseráveis que governos progressistas não podem ignorar. Assim, muitos governos municipais não esperam mais vir as decisões de um novo modelo macro-econômico mas buscam alternativas antimônicas ao modelo atual potencializando vocações e recursos locais. Pinho \& Santana (1998) consideram que a "inovação no setor público no Brasil não pode ser vista fora do contexto de miséria, pobreza, marginalidade, exclusão, clientelismo, paternalismo, etc.". Admitem que "em situação de extrema pobreza, em municípios pobres, os grupos 'marginalizados' não são exceção, mas a regra" e que, assim, governos progressistas não podem ignorá-los.

4. Incorporação dos Excluídos: muito associada à categoria anterior, vários projetos manifestam a intenção e o objetivo explícito de se direcionarem para incorporação de populações excluídas. Esse meta-propósito expressa-se através de várias políticas horizontais, tais como, educação, saúde, políticas agrícolas, etc. Pinho \& Santana (1998) ao se referirem à categoria de inovação incorporação dos excluídos (maioria) e minorias, apontam que "existem casos onde os excluídos não são exatamente a maioria mas formam contingentes apreciáveis, como a questão de crianças e adolescentes de rua em situação de risco, bem como de melhorias no abastecimento alimentar aos carentes, além de incorporação de bóia-frias, e através da qualificação da mão-deobra e da melhoria de condições habitacionais, bem como de crianças em situação de desnutrição crônica". 0 grupo de idosos também tem passado a merecer a atenção de políticas governamentais, mas rompendo com políticas tradicionalistas como tratamento asilar, valorizando os próprios idosos que passam a participarem das decisões que lhes dizem respeito. Existem projetos também com característica não asilar, procurando desenvolver um conjunto de atividades diversificadas para esta comunidade. Projetos específicos vão ainda além deste objetivo fomentando a convivência do idoso com adolescentes "vitalizando" o idoso com esta parceria jovem promovendo "troca de conhecimentos e experiências", elevando a auto-estima e promovendo a inserção social da pessoa idosa. 
O aparecimento de políticas municipais voltadas para idosos, ou a chamada terceira idade, revela que, como se sabe, a população do Brasil envelheceu e que, por outro lado, os setores governamentais tomaram consciência desse fato. A entrada do governo municipal, por sua vez, nesta área poderia estar indicando que as políticas estadual e nacional não têm sido suficientes e/ ou eficazes para enfrentar os problemas da área.

Por último, deve-se registrar que por excluídos entende-se a questão de dois pontos de vista. Em primeiro lugar, excluídos produzidos pelo modelo macro-econômico e político gestado e desenvolvido à nível nacional. Em segundo lugar, excluídos das políticas governamentais. 0 posicionamento de determinados governos municipais indica que o segundo sentido passa a ser atacado, apesar da existência e resistência do primeiro.

Pinho e Santana (1998), destacam a atenção das administrações locais para este contingente populacional que é cada vez mais numeroso e fazendo a observação de que a exclusão social "em determinadas situações precede mesmo a condição de cidadania situando-se no plano humanitário, como por exemplo, a questão da fome e da desnutrição". Moura (1998) também chama a atenção para as iniciativas econômicas locais direcionadas para este segmento populacional que está à margem do mercado.

\section{CONCLUSÕES}

As conclusões a serem tiradas a partir deste material empírico devem ser olhadas com bastante cuidado. Ou seja, a partir da análise desses projetos selecionados não se pode, por exemplo, fazer uma apreciação da descentralização. Assim, este trabalho limita-se a concluir dentro dos seus limites possíveis, apesar de termos tomado uma amostra significativa e bem diversificada de governos municipais no país. Não dá, no entanto, para afirmar que os comportamentos aqui expressos indicam a tendência dos governos municipais como um todo no Brasil. Neste sentido, podemos indiscutivelmente perceber que muitas experiências contrapõem-se frontalmente ao modelo econômico e político adotado no nível federal desenhando-se uma espécie de um welfarismo municipal, obviamente dentro dos estreitos limites de intervenção que este nível pode proporcionar. Ao lado deste welfarismo identificamos também a adoção de um desenvolvimentismo, 
política que o nível federal também não adota. Pode-se apreender que, mais do que welfarismo ou desenvolvimentismo, muitos governos municipais parecem se caracterizarem pelo que poderíamos alcunhar de cidadanismo, ou seja, a prática efetiva da cidadania. Como exemplos deste cidadanismo podemos citar o combate à desnutrição, políticas de saúde e educação que visam tratar todos, mormente os excluídos, como cidadãos.

O governo municipal, através de algumas experiências, também se posiciona contra a postura federal em áreas específicas e estratégicas como o meio-ambiente, promovendo a recuperação e evitando a destruição do "seu" meio-ambiente.

Não se trata aqui de fazer a apologia do nível municipal até porque estas são algumas experiências implementadas geralmente por governos chamados progressistas. Mas nem só de progressismo, no entanto, vive o governo municipal. Isto quer dizer que, localizamos governos mais identificados com ideais democráticos e progressistas, mas ainda sobrevive um amplo espectro de governos conservadores e tradicionais. Mas, pela amostra aqui analisada, verifica-se que o governo municipal exibe comportamento pró-ativo mesmo, apesar de várias adversidades e, um potencial capaz de dar um passo significativo no sentido de contribuir para inocular a democracia e o progressismo em outros níveis de governo, até porque muitas dessas experiências ocorrem em "municípios formadores de opinião", municípios no centro político na nação.

Embora a participação popular, conforme visto anteriormente, ainda seja carente de maior aprofundamento, é inegável que a sociedade civil está em franco processo de articulação com os governos municipais, o nível de governo mais próximo do cidadão. Assim, uma perspectiva otimista enxergaria nesses movimentos um embrião de uma revolução que se deslocaria de baixo para cima incorporando setores da sociedade civil organizada, até grupos empresariais e governos municipais tendo por detrás destes partidos políticos. Uma explicação para isto, além dos partidos ideológicos tomados, parece residir na flexibilidade muito maior do nível municipal que dos demais o que lhe permite inovar e ousar em experiências até laboratoriais de governo.

Também pode-se perceber que os governos municipais têm uma outra percepção da crise e mesmo a falta de recursos financeiros parece não imobilizar estes governos que buscam soluções alternativas, mais baratas, mais simples e fora dos contextos tradicionais, mostrando que "pequenas políticas" podem levar à grande resultados. 0 material analisado 
permite identificar um cardápio bem amplo de intervenções dos governos municipais verificando-se atuações tanto em áreas de carências históricas acumuladas (saúde, educação, habitação, etc) como em áreas específicas da modernidade (meio ambiente, minorias, combate á drogas, apoio á terceira idade, etc.). Isto também quer dizer que não é só a sociedade civil que está em articulação procurando o governo municipal, mas este também está procurando a sociedade civil, o que indicaria que tomou consciência de que não pode governar sozinho.

Ainda, a título de síntese, cabe observar que começa a vingar a idéia de desenvolvimento sustentado, reconhecendo, implicitamente, que não basta combater a desigualdade e injustiças sociais, mas o governo tem que gerar emprego, deflagrar atividades econômicas auto-sustentadas. Começa a propagar-se também a idéia de formação dos consórcios para enfrentamento de problemas comuns a vários municípios.

Em suma, observa-se que, frente ao modelo de "desenvolvimento" adotado nos últimos anos no Brasil, gerador de excludência crescente, contrapõem-se determinados governos municipais que não só contestam esse padrão de desenvolvimento, mas como, também, dentro dos limites de atuação do nível municipal propõem ações que o nível federal não contempla. Parece ser possível identificar uma ebulição no nível municipal que articulado com a organização da sociedade civil pode contestar, no médio prazo, as próprias bases da hegemonia existente a nível federal. Uma última observação, convergente com um alerta colocado no início deste texto, refere-se aos limites da ação governamental municipal. 0 poder municipal não é a tábua de salvação, pois sua competência é restrita, mas pode iniciar um novo posicionamento da sociedade civil frente à problemas sociais capaz de redefinir o escopo das tradicionais ações a nível federal. 


\section{REFERÊNCIAS BIBLIOGRÁFICAS}

ABRUCIO, Fernando Luiz \& COUTO, Cláudio G. A Redefinição do Papel do Estado no Âmbito Local. São Paulo em Perspectiva, Revista da Fundação Seade, vol. 10, no. 3, jul/set/1996, p. 40-47

BAVA, Silvio Caccia. Desenvolvimento Local: uma alternativa para a crise social?. São Paulo em Perspectiva, Revista da Fundação Seade, vol. 10, no. 3, jul/set/1996, p. 53-59.

COSTA, João Bosco Araújo da. A Ressignificação do Local: o imaginário político brasileiro pós-80. São Paulo em Perspectiva, Revista da Fundação Seade, vol. 10, no. 3, jul/set/1996, p. 113-118.

FARAH, Marta F S. Reforma de Políticas Sociais no Brasil: Iniciativas Recentes de Governos Estaduais e Municipais. Paper elaborado para o Seminário Internacional "Reestruturação e Reforma do Estado: Brasil e América Latina no Processo de Globalização", maio/1998, INTERNET, FEA-USP

GENRO, Tarso. Combinar democracia direta e democracia representativa. Desafios do Governo Local. 0 modo petista de governar. São Paulo, Fundação Perseu Abramo, 1997, p. 14-31.

MELO, Marcus André. Crise Federativa, Guerra fiscal e "Hobbesianismo Municipal" efeitos perversos da descentralização?, São Paulo em Perspectiva, Revista da Fundação Seade, vol. 10, no. 3, jul/set/ 1996, p. 11-20.

MOURA, Suzana. A gestão do Desenvolvimento Local: Estratégias e Possibilidades de Financiamento. Salvador: Organizações \& Sociedade, Publicação da Escola de Administração da Universidade Federal da Bahia, vol. 5, no. 12, maio/agos/1998, p. 37- 57.

PINHO, José Antonio G. de \& SANTANA, Mercejane W. Inovação na Gestão Pública no Brasil: uma aproximação teórico-conceitual. In: Enanpad , 22, Anais, Foz do Iguaçu, 1998.

SALGADO, Silvia Regina da Costa. Experiências Municipais e Desenvolvimento Local. São Paulo em Perspectiva, Revista da Fundação Seade, vol. 10, no. 3, jul/set/1996, p. 48-52.

SOUZA, Celina. Reinventado o Poder Local: limites e possibilidades do federalismo e da descentralização. São Paulo em Perspectiva, Revista da Fundação Seade, vol. 10, no. 3, jul/set/ 1996, p. 103-112. 
TENÓRIO, Fernando G. \& ROZENBERG, Jacob E. "Gestão Pública e Cidadania: Metodologias Participativas em Ação". Cadernos Gestão Pública e Cidadania. Vol. 7, São Paulo, FGV, 1997.

TENÕRIO, Fernando G. \& CUNHA, Augusto P G. Relatório sobre as experiências semifinalistas do Programa Gestão Pública e Cidadania - ciclo de premiação, 1997. Cadernos Gestão Pública e Cidadania. Vol. 10, São Paulo, FGV, 1998

TENÓRIO, Fernando G. Inovando com democracia, ainda uma utopia. Rio de Janeiro, Revista de Administração Pública, 33 (6), nov./dez. 1999, p. 229-238.

TENÓRIO, Fernando G. \& STONIO, Gylcilene R. A Sociedade é protagonista na relação como o Estado?. Cadernos Gestão Pública e Cidadania. Vol. 15, São Paulo, FGV, 2000. 